\title{
IMAGERY AND GIS: BEST PRACTICES FOR EXTRACTING INFORMATION FROM IMAGERY
}

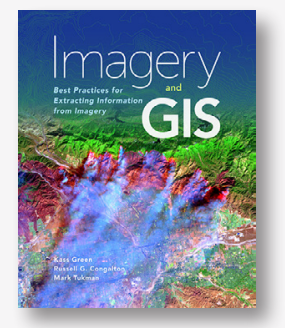

By Kass Green, Russell G. Congalton, and Mark Tukman

Esri Press, 2017

437 pages, \$99.99, softcover.

ISBN: 978-1-58948-454-2

Review by: Jörn Seemann, Ball State University

Aerial photos and satellite images are fascinating sources for mapmakers since they can make the invisible visible and allow the extraction of important data for maps and GIS databases.

One of my first encounters with the literature on remote sensing and image processing was the second edition of Remote Sensing and Image Interpretation by Lillesand and Kiefer (1987). I eagerly wallowed through the more than 700 pages and jotted down notes on how to process, enhance, and classify satellite images step-by-step. That book contained mainly black-and white illustrations, but in the mid-section, the authors included about two score of color plates. Among these was one that drew my attention: the comparison between a panchromatic and an infrared image of Camp Randall Stadium at the University of Wisconsin-Madison. The IR film photo revealed the treachery of images: the turf of the football field was synthetic and not real grass.

For both of these reasons - their utility and the treachery-the production of maps frequently requires practical knowledge of how to prepare images.

There is no shortage of introductory textbooks about image processing on the market. Classic remote sensing texts such as Fundamentals of Remote Sensing and Airphoto Interpretation (Avery and Berlin 1992) and Introduction to Remote Sensing (Campbell and Wynn 2011) have been published in multiple editions, and specialized uses of satellite images in archeology (Forte and Campana 2016), the environment (Jensen 2013), urban planning (Yang 2011), and other fields, have also received book-length studies.
Imagery plays an essential part in a wide variety of geospatial projects involving GIS, GPS tracking, databases, online apps, and, of course, cartography.

Imagery and GIS proposes to teach readers "about the many ways that imagery brings value to GIS projects and how GIS can be used to derive value from imagery" (3), and the book provides useful insights into successfully preparing and integrating images into GIS and maps, and in support of analysis. Each of the the three authors: Kass Green, Russell Congalton, and Mark Tukman, can look back on decades of professional experience and research on the application of remotely-sensed imagery to real-world situations.

The authors mention three principal utilizations of imagery in a GIS environment: "as a base image to aid the visualization of map information," "as an attribute of a feature," or "as a data source from which information is extracted through the process of image classification" (21).

The latter use type-the preparation of images for applications-is the focus of this book.

The book is divided into four sections that correspond to the common sequence of a typical imagery project workflow: selection, processing, information extraction, and effective management. In the four chapters of the first section, entitled "Discovering Imagery," the authors present general ideas about the structure of images, fundamentals of remote sensing (electromagnetic spectrum, sensors, resolution, platforms, etc.), and some tips and checklists to help users select appropriate images for their specific projects.

Section 2 ("Using Imagery") has two long chapters that deal with the basics of image manipulation, including discussions of formats and properties, image enhancement, mosaicking, radiometric correction, and georeferencing. "Extracting Information from Imagery" is the third section, and discusses the information extraction process. Its five chapters provide an emphasis on diverse interpretation 
strategies, classification methods, and modeling techniques that help readers interpret and compare data in different space settings and time frames. The last section is made up of three chapters dedicated to the management of imagery and GIS data; accuracy issues, ArcGIS mosaic datasets; and the storage, publishing, and sharing of images in cloud platforms.

A final chapter, "Concluding Thoughts," offers "some nuggets of wisdom" (385) that the authors have gathered over their long experience in remote sensing research and their participation in many mapping projects. The twenty tips, laid out in bullet point format, address topics like the need for a well-crafted classification scheme; the best uses of high-resolution, hyperspectral, and lidar imagery in GIS projects; the importance of scripting in facilitating workflows; and the advantages of web technologies and services.

The text of the more than 400 pages of Imagery and GIS is printed in a generously spaced, easy-to-read sans-serif font that is interspersed with more than 150 figures and over a dozen tables. There are a large number of examples from different places in the United States, including an ArcGIS swipe map comparing before and after the 2016 flooding in Louisiana (315), woody debris monitoring in Vermont's Great Brook (81-83), and a very detailed look at the Sonoma County Vegetation and Habitat Mapping Program. The authors tell us that "over 30 of these figures are linked to external interactive applications, which allow you to explore the concepts in more depth" (9). Many of the URLs in the book lead to examples compiled for the Esri Landsat Explorer web app (landsatexplorer.esri.com). "Imagery and GIS Web Apps" is a set of Esri story maps, hosting fourteen different applications that allow interactive exploration and comparison of resolution, filters, temporal sequences, radar imagery, and many other topics discussed in the book. Most of these interactive maps include action buttons that allow the user to engage and "play" with the imagery by selecting a filter or defining a mask, or actively switching and "swiping" between two images from different periods. In their book, the authors provide information on how to explore these images. In addition to this, the web app hosts continuously updated versions of tables 4.2 and 4.3 from the book, which list and compare current and future commercial high- and very-high spatial resolution satellite products.
Besides these web resources, the reader is informed about other features and applications such as the Collector for ArcGIS tool (detailed use guidelines for which are included in the book). There are a lot of examples in the book and on line, but more detailed explanations, additional questions or even a few exercises would further enrich the experience.

While the numerous online resources are useful, they are not always convenient to access. It would be preferable to bring more of this material into the book itself. In the case of the Sonoma County study, however, the inclusion of 28 pages of text defining vegetation type hierarchies and listing dozens of Sonoma County plant and tree species with their botanical characteristics, habitats, and Latin names might not be absolutely necessary to illustrate "the importance of developing a robust classification scheme” (190).

This is a light and easy read that gently introduces the reader, who may not be very familiar with the world of satellite images, to basic concepts of image processing and enhancement for GIS. In addition to this, the 150-plus entry glossary is a useful aid to understanding the very specific terminology of remote sensing. However, it must be said that the book is mainly about the preparation of images for GIS use and not specifically about the use of imagery in GIS projects. The emphasis is on the creation of image data rather than its practical application. This is not a workbook with hands-on exercises, but a decision-making aid and an introduction to concepts, methods, and processes.

In comparison to other publications on the market, Imagery and GIS is far less technical and detailed than, for example, Elements of Photogrammetry with Applications in GIS (Wolff, DeWitt, and Wilkinson 2014) or Image Processing and GIS for Remote Sensing: Techniques and Applications (Liu and Mason 2016). At the same time, it is less practical and engaging than Making Spatial Decisions Using GIS and Remote Sensing (Keeranen and Kolvoord 2014), and less visual and popular than The ArcGIS Imagery Book (Brown and Harder 2016). None of this implies that this book is inferior to the others, but rather that it finds a useful kind of middle way approach. Imagery and GIS is an introduction to the fascinating world of spatial imagery for those readers who want to get a basic idea about remote sensing, image processing, and how images are prepared 
for GIS projects. Keeping in mind this limited aim, the authors deliver their message clearly and in a very comprehensive manner. Images are gaining increasing importance in mapping projects and GIS databases and these pictures can, literally, be worth more than a thousand words when it comes to mapmaking.

\section{REFERENCES}

Avery, Thomas, and Graydon Berlin. 1992. Fundamentals of Remote Sensing and Airphoto Interpretation, Fifth Edition. Upper Saddle River, NJ: Prentice Hall.

Brown, Clint, and Christian Harder. 2016. The ArcGIS Imagery Book: New View. New Vision. Redlands, CA: Esri Press.

Campbell, James, and Randolph Wynn. 2011. Introduction to Remote Sensing, Fifth Edition. New York: Guilford Press.

Forte, Maurizio, and Stefano Campana, eds. 2016. Digital Methods and Remote Sensing in Archaeology: Archaeology in the Age of Sensing. Berlin: Springer. doi: 10.1007/978-3-319-40658-9.
Jensen, John. 2007. Remote Sensing of the Environment: An Earth Resource Perspective, Second Edition. Upper Saddle River, NJ: Prentice Hall.

Keeranen, Kathryn, and Robert Kolvoord. 2014. Making Spatial Decisions Using GIS and Remote Sensing: A Workbook. Redlands, CA: Esri Press.

Lillesand, Thomas, and Ralph Kiefer. 1987. Remote Sensing and Image Interpretation, Second Edition. New York: Wiley.

Liu, Jian Guo, and Phillippa Mason. 2016. Image Processing and GIS for Remote Sensing: Techniques and Applications. Oxford: Wiley-Blackwell. doi: $10.1002 / 9781118724194$.

Wolff, Paul, Bon DeWitt, and Benjamin Wilkinson. 2014. Elements of Photogrammetry with Applications in GIS, Fourth Edition. New York: McGraw Hill.

Yang, Xiaojun. 2011. Urban Remote Sensing: Monitoring, Synthesis and Modeling in the Urban Environment. Oxford: Wiley-Blackwell. doi: 10.1002/9780470979563.

\section{ECOLOGICAL ATLAS OF THE BERING, CHUKCHI, AND BEAUFORT SEAS, SECOND EDITION}

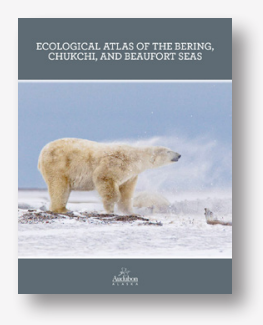

Edited by Melanie A. Smith, Max S. Goldman, Erika J. Knight, and Jon J. Warrenchuk; Cartography by Daniel P. Huffman

Audubon Alaska, 2017

332 pages, $100+$ maps, and 100+ illustrations; \$105, softcover.

Free PDF download: ak.audubon.org/conservation/downloadecological-atlas-bering-chukchi-and-beaufort-seas

Review by: Daniel Cole, Smithsonian Institution

This handsome book begins with an invitation to imagine various scenes of human-wildlife interaction in the Arctic. The editors, led by Melanie Smith of Audubon Alaska, want the readers to explore these and other Arctic marine scenes. Their goal, as set out in the opening paragraphs of the Introduction, "is to create a comprehensive, trans-boundary atlas that represents the current state of knowledge on subjects ranging from physical oceanography to species ecology to human uses" (2). This review will evaluate whether or not the atlas, and especially its maps, has achieved this goal.

The rest of the Introduction addresses a range of basic issues, including how the Arctic is managed, both nationally and internationally. It also provides a review of historic cartographic endeavors by the National Oceanic and Atmospheric Administration (NOAA) and by Audubon Alaska, followed by a discussion of mapping methods and challenges that includes issues of data quality and knowledge gaps. The section Use of Traditional Knowledge and Subsistence Datasets tells how the atlas content was reviewed by Bering Strait tribes, and is a critical inclusion.

The first map in the atlas is on page 9, and is a map of North America made in 1812 that shows the Bering and the southern Chukchi Seas, but nothing at all of the Beaufort. An accompanying inset of a Google Earth-like 